\title{
A Comprehensive Evaluation Model of the Course of Electronic Technology based on Outcomes-based Education
}

\author{
Yang Zhao \\ Department of Mechanical and Electrical Engineering, Guangdong University of Science \& \\ Technology, Dongguan, China \\ zhaoyangmatp@163.com
}

\begin{abstract}
Keywords: Comprehensive evaluation; Course of electronic technology; Outcomes-based education; Correlation degree analysis
\end{abstract}

\begin{abstract}
According to the theory and practice of light weight, the process of teaching of electronic technology course in practical ability training is not enough in modern teaching methods of curriculum evaluation. The results oriented curriculum development theory put forward the reform of the teaching goal, the curriculum content, methods and assessment form. After the reform, the teaching plan of electronic technology is more suitable for the concept of international engineering education accreditation. The knowledge system is clearer, and the assessment form is more reasonable, which plays a positive role in improving students' engineering design ability, engineering practice ability and engineering innovation ability.
\end{abstract}

\section{Introduction}

The course of electronic technology based on outcomes-based education (OBE) involves a wide range, strong practicality and systematic characteristics[1-3]. Therefore, the quality evaluation system of OBE is also a systematic project with great difficulty and high technical meaning. The quality assessment tool plays a very important role in relation to the course quality results[4-5]. In order to improve the course quality and the overall quality of teaching, universities are trying hard to study and construct scientific evaluation index system[6-7]. Specifically, the electronic technology teaching evaluation system is the main elements and results with the corresponding assessment tools on each teaching of systematic assessment and evaluation activities with the role orientation, diagnosis, incentive, which has the significant influence to enhance the comprehensive national strength[8]. In recent years, the education sector also requires improved supervision continues to strengthen the teaching quality. Therefore, it is the internal demand of the development of the times to further standardize the evaluation index of education teaching quality under the environment of improving the quality of higher education.

The course of electronic technology based on OBE has been greatly popularized in all subjects[9-10]. Based on this, the discussion and the research on the course of electronic technology based on OBE have been called the hot topics. The emerging of OBE determines its immaturity and there also exist some problems that the teachers do not make full use of its advantages and the students do not really learn to use the software. The normalization of OBE has been studied and put forward some improving suggestions. The concept of value theory has been employed to analyze the deficiency in the researches of OBE and think of the significance of the course of electronic technology based on OBE.

\section{Comprehensive Evaluation Model}

The correlation degree analysis method in system theory is a new quantification method to measure the correlation degree of measurement factors and it is a comparison for the relationship of statistical data lists. In this paper, the correlation analysis method has been employed to establish the comprehensive evaluation model with the least squares criterion.

Attribute Matrix. Assuming that there are $m$ evaluation objects in the system and each object has $n$ evaluation factors. The composition of attribute value of each evaluation object in the corresponding evaluation factor is shown in the attribute matrix in formula (1). 


$$
X=\left[\begin{array}{cccc}
x_{11} & x_{12} & \cdots & x_{1 n} \\
x_{21} & x_{22} & \cdots & x_{2 n} \\
\cdots & \cdots & \cdots & \cdots \\
x_{m 1} & x_{m 2} & \cdots & x_{m n}
\end{array}\right]=\left(x_{i j}\right)_{m \times n}
$$

In formula (1), $x_{i j}$ represents the index attribute value $f$ the $i$ th evaluation object in the $j$ th evaluation factor. In this paper, there are 11 evaluation objects for the computer assisted information teaching and the related factors. The evaluation factors are the data in 2014, 2015, 2016 and 2017. Therefore, in this paper $n=4, m=12$ and the element is the data value of corresponding item, then $X=\left(x_{i j}\right)_{1 \times 4}$.

Normalized Matrix. The normalized matrix can be understood as the matrix after data standardization. The calculation methods are shown in formula (2), (3) and (4).

$$
\begin{aligned}
& x_{i j}^{*}=\frac{x_{i j}-\min x_{i j}}{\max x_{i j}-\min x_{i j}} \\
& x_{i j}^{*}=\frac{\max x_{i j}-x_{i j}}{\max x_{i j}-\min x_{i j}} \\
& x_{i j}^{*}=1-\frac{\left|x_{i j}-\gamma_{i}\right|}{\max \left|x_{i j}-\gamma_{i}\right|}
\end{aligned}
$$

In formula (2), (3) and (4), $x_{i j}^{*}$ represents the matrix element after standarization and $0 \leq x_{i j}^{*} \leq 1$. In formula (4), $\gamma_{i}$ refers to the standard value of the $i$ th object. In order to get the maximum value and the minimum value of each object to define the two vectors which are respectively the system optimal vector $\vec{G}$ and the system sub-vector $\vec{B}$ and that can be shown in formula (5).

$$
\left\{\begin{array}{l}
\vec{G}=\left(g_{1}, g_{2}, \cdots, g_{m}\right) \\
=\left(x_{11}{ }^{*} \vee x_{12}{ }^{*} \vee \ldots \vee x_{1 n}{ }^{*}, x_{21}{ }^{*} \vee x_{22}{ }^{*} \vee \ldots \vee x_{2 n}{ }^{*}, \ldots, x_{m 1}{ }^{*} \vee x_{m 2}{ }^{*} \vee \ldots \vee x_{m n}{ }^{*}\right) \\
\vec{B}=\left(b_{1}, b_{2}, \cdots, b_{m}\right) \\
=\left(x_{11}{ }^{*} \vee x_{12}{ }^{*} \vee \ldots \vee x_{1 n}{ }^{*}, x_{21}{ }^{*} \vee x_{22}{ }^{*} \vee \ldots \vee x_{2 n}{ }^{*}, \ldots, x_{m 1}{ }^{*} \vee x_{m 2}{ }^{*} \vee \ldots \vee x_{m n}{ }^{*}\right)
\end{array}\right.
$$

In formula (6), $\wedge, \vee$ respectively refer to the small and large operators, $g_{i}=\max \left\{x_{i 1}{ }^{*}, x_{i 2}{ }^{*}, \cdots, x_{i m}{ }^{*}\right\}$. $b_{i}=\min \left\{x_{i 1}{ }^{*}, x_{i 2}{ }^{*}, \cdots, x_{i m}{ }^{*}\right\}$, this method has been employed in this paper and the standard value takes the average value of the factor values of this object.

Correlation Degree Analysis. The data normalization processing of factors has been used to get the weight vectors of evaluation factors, which is shown in formula (6).

$$
\vec{W}=\left(\omega_{1}, \omega_{2}, \cdots, \omega_{n}\right), \sum_{i=1}^{n} \omega_{i}=1
$$

The correlation degree between $\vec{X}_{j}$ and optimal vector $\vec{G}$ as well as $\vec{X}_{j}$ and sub vector $\vec{B}$ is shown in formula (10).

$$
\left\{\begin{array}{l}
v\left(\vec{X}_{j}, \vec{G}\right)=\sum_{i=1}^{n} \omega_{i} \xi_{i}\left(\vec{X}_{j}, \vec{G}\right) \\
v\left(\vec{X}_{j}, \vec{B}\right)=\sum_{i=1}^{n} \omega_{i} \xi_{i}\left(\vec{X}_{j}, \vec{B}\right)
\end{array}\right.
$$


The comparison between the traditional teaching theory and the OBE teaching theory is shown in Table 1.

Table 1 Comparison between the traditional teaching theory and the OBE teaching theory

\begin{tabular}{|c|c|c|}
\hline Category & Traditional teaching theory & OBE teaching theory \\
\hline Teaching mode & $\begin{array}{l}\text { Teacher-fronted and } \\
\text { student-supplemented }\end{array}$ & $\begin{array}{l}\text { Student-fronted and independent } \\
\text { learning }\end{array}$ \\
\hline Role of teacher & $\begin{array}{l}\text { Knowledge transmitter and } \\
\text { inculcator }\end{array}$ & Knowledge guider \\
\hline Role of learner & Passively accepting & Self-construction \\
\hline $\begin{array}{l}\text { Knowledge } \\
\text { concept }\end{array}$ & Static, objective and confirmed & Dynamic, subjective and context \\
\hline Learning form & Individual learning oriented & $\begin{array}{l}\text { Interaction between teachers and } \\
\text { students, interaction among } \\
\text { students }\end{array}$ \\
\hline Learning process & $\begin{array}{c}\text { Passive absorption and repeated } \\
\text { practice }\end{array}$ & $\begin{array}{l}\text { Active exploration and } \\
\text { self-discovery }\end{array}$ \\
\hline $\begin{array}{l}\text { Learning } \\
\text { motivation }\end{array}$ & Extrinsic motivation oriented & Intrinsic motivation oriented \\
\hline Teaching media & $\begin{array}{c}\text { Teaching methods and means of } \\
\text { teachers }\end{array}$ & $\begin{array}{l}\text { Self-learning and exploration tools } \\
\text { for students }\end{array}$ \\
\hline Teaching process & $\begin{array}{c}\text { Transmitting and inculcating of } \\
\text { knowledge }\end{array}$ & $\begin{array}{l}\text { Processing and transformation of } \\
\text { knowledge }\end{array}$ \\
\hline $\begin{array}{l}\text { Teaching } \\
\text { contents }\end{array}$ & $\begin{array}{l}\text { Teaching material oriented, } \\
\text { stressing intellectual development }\end{array}$ & $\begin{array}{l}\text { Combining with teaching } \\
\text { materials and cultivating the } \\
\text { integrity of personality }\end{array}$ \\
\hline $\begin{array}{l}\text { Teaching } \\
\text { evaluation }\end{array}$ & Termination evaluation & $\begin{array}{c}\text { Combination of termination and } \\
\text { process evaluation }\end{array}$ \\
\hline
\end{tabular}

The methods of questionnaire survey and expert scoring have been employed to conduct the index quantization in view of the traditional electronic technology teaching method and the OBE method. For example, the scores of 11 index quantification are 10 points and the total scores of questionnaire survey results are 110 points. The obtained scores should be conducted the single-indicator average processing for the issued 500 questionnaires. The total scores of the evaluation of seven experts are also 10 points and the average value without the highest score and the lowest score is considered as the index scores. The scores of each index of the two teaching methods in 2014, 2015, 2016 and 2017 are shown in Table 2 . 
Table 2 Scores of each index

\begin{tabular}{ccccccccc}
\hline & \multicolumn{2}{c}{2014} & \multicolumn{2}{c}{2015} & \multicolumn{2}{c}{2016} & \multicolumn{2}{c}{2017} \\
\cline { 2 - 8 } Index & $\begin{array}{c}\text { Experien } \\
\text { ce group }\end{array}$ & $\begin{array}{c}\text { Control } \\
\text { group }\end{array}$ & $\begin{array}{c}\text { Experienc } \\
\text { e group }\end{array}$ & $\begin{array}{c}\text { Control } \\
\text { group }\end{array}$ & $\begin{array}{c}\text { Experien } \\
\text { ce group }\end{array}$ & $\begin{array}{c}\text { Control } \\
\text { group }\end{array}$ & $\begin{array}{c}\text { Experien } \\
\text { ce group }\end{array}$ & $\begin{array}{c}\text { Control } \\
\text { group }\end{array}$ \\
\hline X11 & 8.29 & 5.58 & 8.25 & 5.11 & 8.05 & 6.14 & 9.09 & 8.31 \\
X12 & 7.74 & 6.17 & 5.30 & 6.87 & 6.04 & 8.54 & 6.58 & 9.69 \\
X13 & 8.75 & 5.67 & 9.38 & 5.16 & 9.95 & 8.00 & 5.11 & 5.25 \\
X14 & 6.13 & 6.55 & 8.33 & 9.23 & 6.73 & 5.72 & 6.98 & 5.30 \\
X15 & 6.53 & 7.65 & 8.68 & 5.41 & 7.72 & 7.82 & 6.93 & 8.52 \\
X21 & 8.31 & 7.28 & 6.33 & 9.96 & 7.60 & 8.94 & 6.94 & 7.83 \\
X22 & 6.14 & 7.30 & 7.62 & 8.70 & 9.19 & 5.66 & 6.71 & 9.81 \\
X23 & 9.41 & 6.08 & 6.00 & 9.69 & 9.93 & 6.07 & 6.52 & 7.08 \\
X24 & 8.50 & 8.20 & 7.49 & 8.30 & 6.21 & 9.54 & 8.68 & 5.81 \\
X31 & 8.81 & 6.15 & 8.68 & 8.56 & 6.98 & 7.47 & 8.25 & 5.68 \\
X32 & 5.56 & 5.34 & 6.30 & 6.55 & 5.83 & 5.91 & 5.80 & 8.79 \\
\hline
\end{tabular}

According to formula (6), the weight vector matrix can be shown in Table 3.

Table 3 Weight vector matrix

\begin{tabular}{lllll}
\hline Index & 2012 & 2013 & 2014 & 2015 \\
\hline X11 & 0.10 & 0.09 & 0.07 & 0.06 \\
X12 & 0.12 & 0.09 & 0.07 & 0.10 \\
X13 & 0.06 & 0.09 & 0.09 & 0.08 \\
X14 & 0.06 & 0.08 & 0.07 & 0.10 \\
X15 & 0.10 & 0.09 & 0.11 & 0.12 \\
X21 & 0.10 & 0.10 & 0.09 & 0.11 \\
X22 & 0.12 & 0.08 & 0.09 & 0.10 \\
X23 & 0.09 & 0.11 & 0.08 & 0.06 \\
X24 & 0.07 & 0.10 & 0.09 & 0.09 \\
X31 & 0.07 & 0.06 & 0.11 & 0.10 \\
X32 & 0.11 & 0.10 & 0.13 & 0.08 \\
\hline
\end{tabular}

\section{Summary}

In short, the conventional quality evaluation of teaching has obvious shortcomings, and the main problem in teaching evaluation index is abstract and poor feasibility. According to the research activities carried out on the stage of college students in China and the related knowledge, in order to better enhance the quality of physical education and improve the overall quality of students, the quality evaluation index of design should attach great importance to the students, fully consider the impact of various factors and evaluate index hierarchically set the teaching quality. At the same time, reasonable application of evaluation index system enhance the awareness of all teachers and students for knowledge and attention.

\section{References}

[1] Ravenscroft, A. Schmidt, J. Cook, and C. Bradley. Designing Social Media for Informal Learning and Knowledge Maturing in the Digital Workplace, Journal of Computer Assisted Learning, 28 (2012), 112-120. 
[2] JY Nancy, NH Khanna, and K Arputharaj. A Q-back propagated time delay neural network for diagnosing severity of gait disturbances in Parkinson's disease, Journal of Biomedical Informatics, 60 (2016), 169-176.

[3] BBC Onwuagboke, and TKR Singh. Effects of Computer Self-Efficacy on Pre-Service Art Teachers' Achievement in Graphic Design, Pertanika Journal of Social Science \& Humanities, 24 (2016), 1315-1333.

[4] BR Webb, and SB Gallagher. Mapping Commonalities and Differences in Software Engineering and Graphic Design Approaches to Multimedia Systems Development, Journal of Computer Information Systems, 46 (2016), 87-98.

[5] S Laing, and M Masoodian. A study of the influence of visual imagery on graphic design ideation, Design Studies, 45 (2016), 187-209.

[6] S Narayanakumar, and K Raja. A BP Artificial Neural Network Model for Earthquake Magnitude Prediction in Himalayas, Circuits \& Systems, 7 (2016), 3456-3468.

[7] C Bergmeir, and JM Benitez. Neural Networks in R Using the Stuttgart Neural Network Simulator: RSNNS, Carpathian Journal of Electronic \& Computer Engineering, 46 (2016), 3-6.

[8] A Graves, G Wayne, M Reynolds, T Harley, and I Danihelka. Hybrid computing using a neural network with dynamic external memory, Nature, 538 (2016) :471.

[9] M Hernández-Pajares, JM Juan, and J Sanz. Neural network modeling of the ionospheric electron content at global scale using GPS data, Radio Science, 32 (2016), 1081-1089.

[10] A Shafiee, A Nag, N Muralimanohar, R Balasubramonian, JP Strachan. ISAAC: A Convolutional Neural Network Accelerator with In-Situ Analog Arithmetic in Crossbars, Acm Sigarch Computer Architecture News, 44 (2016), 14-26. 